\title{
Manifestaciones orales en pacientes con COVID-19
}

\section{Oral manifestations in patients with COVID-19}

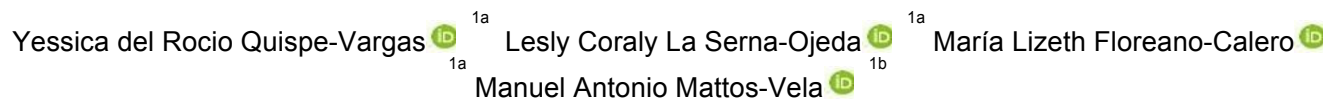

\section{RESUMEN}

El coronavirus de tipo 2 causante del síndrome respiratorio agudo severo (SARS-CoV-2), agente causal del COVID-19, se encuentra en la saliva en un gran porcentaje y esta juega un papel importante como transmisora de la infección por SARSCoV-2. Por lo tanto, la cavidad oral podría ser un reservorio para el virus SARS-CoV-2 debido a la alta afinidad que tiene este virus por las células con receptores para la enzima convertidora de angiotensina 2 (ECA 2) y el ácido siálico, pudiendo afectar, de este modo, el funcionamiento de las glándulas salivales, las sensaciones del gusto, olfato y la integridad de la mucosa oral. Se han registrado manifestaciones clínicas entre signos y síntomas que han contribuido a comprender el comportamiento de este virus SARS-CoV-2; de las cuales se han reportado en un gran porcentaje, a la disgeusia, ageusia, hipogeusia y la sequedad de la boca entre las principales manifestaciones orales; sin embargo, hay una información deficiente en relación a las manifestaciones orales en pacientes con COVID-19. El objetivo de esta revisión es identificar las posibles manifestaciones orales en pacientes con COVID-19, mediante la recopilación de la información y presentación actualizada de la literatura.

Palabras clave: COVID-19; Manifestaciones bucales; Cavidad bucal. (Fuente: DeCS BIREME)

\section{ABSTRACT}

The severe acute respiratory syndrome type 2 coronavirus (SARS-Cov-2) the causative agent of COVID-19, is found in saliva in a large percentage and saliva plays an important role as a transmitter of SARS-Cov-2 infection. Therefore, the oral cavity could be a reservoir for SARS-Cov-2 virus due to the hight affinity of this virus for cells with receptors for angiotensinconverting enzyme (ACE 2) and sialic acid, thus affecting the functioning of the salivary glands, taste sensations, smell and the integrity of the muco oral. Clinical manifestations have been reported among signs and symtoms that have contributed to understand the behavior of this SARS- Cov-2 virus; of wich dysgeusia, ageusia, hipogeusia and dry mouth have been reported in a large percentage among the main oral manifestation; however, there is a lack of information regarding oral manifestations in patients with COVID-19. The aim of this review is to identify the possible oral manifestations in patients with COVID-19 by compiling the information and presenting an uptaded presentation of the literature.

Key words: COVID 19; Oral manifestations; Oral cavity. (Source: MeSH NLM)

Recibido: 13 de Marzo de 2021

Aprobado: 05 de Julio de 2021

Publicado: 08 de Julio de 2021

${ }^{1}$ Universidad Nacional Mayor de San Marcos. Lima Perú

astudiante

${ }^{\mathrm{b}}$ Docente

Correspondencia:

Yessica del Rocío Quispe Vargas

Dirección: Germán Amezaga 375, Cercado. Lima-Perú

Correo electrónico: yessica.quispe@unmsm.edu.pe
Este es un artículo de acceso abierto distribuido bajo la licencia Creative Commons Atribución 4.0 Internacional (CC BY 4.0)

https://creativecommons.org/licenses/by/4.0/deed.

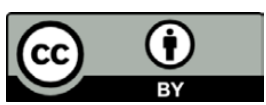

Citar como: Quispe Vargas YR, La Serna Ojeda LC, Floreano Calero ML, Mattos Vela MA. Manifestaciones orales en pacientes con COVID-19. KIRU. 2021 Jul-Sep; 18(3): 194- 202. https://doi.org/10.24265/kiru.2021.v18n3.09 


\section{INTRODUCCIÓN}

La pandemia del COVID-19 ha tenido un impacto en todo el mundo en diferentes ámbitos, dando paso a una severa crisis social, económica y de salud sin precedentes como resultado del modo de propagación de la infección, el número de muertes a nivel global y el síndrome respiratorio agudo severo resultante ${ }^{(1)}$.

El coronavirus de tipo 2 causante del síndrome respiratorio agudo severo (SARS-CoV-2), agente causal del COVID-19, se encuentra en la saliva en un gran porcentaje y se transmite de persona a persona a través de gotitas de saliva, expulsadas al estornudar, hablar, toser o respirar ${ }^{(2)}$, lo que indica que la mucosa oral puede ser el primer escenario de infección con SARS-CoV-2 trayendo como consecuencia el incremento de casos clínicos y su rápida propagación.

La información disponible respalda que la mucosa oral es un sitio inicial de entrada para el agente causal del COVID-19, por ello, las principales manifestaciones clínicas entre signos y síntomas producidas por el virus SARS-CoV-2, son orales, incluida la pérdida del gusto/ olfato y sequedad de boca, siendo estos considerados síntomas tempranos de COVID-19, antes que otros síntomas generales como fiebre, dificultad respiratoria, diarrea $y$ tos, que permite comprender el comportamiento de este virus; sin embargo, aquella información sobre los síntomas reportados recientemente a nivel oral es deficiente (3). Por lo que el odontólogo debe estar informado y preparado para desempeñar un papel más activo en la identificación y el diagnóstico temprano de pacientes con COVID-19 mediante las manifestaciones que pueda expresar esta enfermedad en la cavidad bucal, por ello, la presente revisión tiene el objetivo de identificar las posibles manifestaciones orales en pacientes con COVID-19.

\section{METODOLOGÍA}

Las bases de datos consultadas fueron SciELO, Redalyc, Latindex y LILACS. Así mismo, la selección de información para este estudio se basó en artículos originales, artículos de revisión, cartas al editor y reportes de casos clínicos relacionados con "manifestaciones orales" y "COVID-19" en español e inglés de enero a diciembre del 2020.

\section{COVID-19}

La COVID-19 es una enfermedad infecciosa causada por un coronavirus recién descubierto. El patógeno causante se identificó como el síndrome respiratorio agudo severo coronavirus 2 (SARSCoV-2), que es el séptimo tipo de la familia de los coronavirus que afecta a los humanos ${ }^{(4)}$. Debido a su rápida propagación por diferentes países y su alta tasa de letalidad fue denominada por la Organización Mundial de la Salud (OMS) una emergencia de salud pública de preocupación internacional, por lo que es declarada como una pandemia que amenaza la salud pública.

EI virus SARS-CoV-2, que específicamente pertenece a la familia Coronaviridae, del orden Nidovirales, tienen un material genético de ARN de cadena sencilla (monocatenario) de polaridad positiva [(+) ss ARN], con un tamaño de 27-32 kilobases, y cuatro proteínas estructurales, de las cuales la proteína Spike (S) representa la estructura más grande del virus y son esenciales para la entrada en las células huésped ${ }^{(5)}$. El nuevo coronavirus SARS-CoV-2, como otros coronavirus, tienen una alta probabilidad de tener un origen zoonótico, estos se pueden diferenciar en cuatro géneros: alfa, beta, delta y gamma, de los cuales $\alpha-\mathrm{CoV}$ y $\beta$-CoV tienden a infectar a los humanos, principalmente a los sistemas respiratorio, gastrointestinal y nervioso central ${ }^{(6)}$.

\section{Mecanismos de transmisión}

El mecanismo utilizado para la transmisión del SARS-CoV-2 se da principalmente, a través de las gotitas de Flügge o secreción nasal de más de 5 micras, que son capaces de transmitirse a distancias de hasta 2 metros desde el tracto respiratorio a la cavidad bucal ${ }^{(7)}$. Así mismo, el SARS-CoV-2 que también está presente en la sangre, puede acceder a la cavidad bucal, ya que este virus se libera a la saliva mediante el epitelio de los ductos a través del líquido crevicular o por infección de las glándulas salivales ${ }^{(8)}$.

EI COVID-19 está asociado con la transmisión por contacto directo o cercano de persona a persona que se da mediante el contacto de fluidos salivales provenientes de tos, estornudos y gotitas de saliva ${ }^{(9)}$. De igual modo, el COVID-19 puede propagarse mediante la transmisión de contacto indirecto que se produce al extenderse en las manos, fómites que se encuentran en el entorno de una persona infectada y luego entrar en contacto con la cavidad bucal, nasal, ocular y otras membranas mucosas ${ }^{(10)}$.

\section{Mecanismos de Infección}

El primer paso de la infección por coronavirus es la entrada del virus en las 
células. El SARS-CoV-2 es conocido por su interacción con el receptor de la enzima convertidora de angiotensina 2 (ACE2), ya que esta facilita su penetración en las células epiteliales de la mucosa oral y el cerebro ${ }^{(11)}$. La ACE2 es el principal receptor de la célula huésped para el agente etiológico de la COVID-19; este receptor se encuentra altamente expresado en las células epiteliales de la lengua, las glándulas salivales y todo el tracto respiratorio, provocando que la cavidad oral sea susceptible a la infección de SARS-CoV-2 ${ }^{(12)}$.

El ácido siálico, componente esencial de la mucina salival encargado de proteger las glucoproteínas que transmiten moléculas gustativas durante el proceso de la digestión, tiene afinidad con el SARS-CoV-2 ya que ocupa los sitios de unión del ácido siálico en las papilas gustativas, causando alteraciones en la percepción del gusto y el sentido del olfato ${ }^{(8)}$. Se puede notar que la saliva juega un papel importante como transmisora de la infección por SARS-CoV-2, por este motivo, los odontólogos serían los primeros en identificar a pacientes sospechosos del nuevo coronavirus mediante las posibles manifestaciones orales que expresa el COVID-19. Por ende, es necesario que los profesionales de la salud oral estén informados y preparados para identificar las manifestaciones orales que presenta esta enfermedad para poder orientar a sus pacientes a realizarse las pruebas adecuadas y tratamientos con un diagnóstico temprano.

\section{Manifestaciones orales en pacientes con COVID-19}

En pacientes con COVID-19 las lesiones producidas por el proceso de inflamación debido a la acción viral, desencadena una inflamación vascular ${ }^{(13)}$ y provoca un desequilibrio que puede llegar a comprometer algunos órganos del cuerpo. Es así que la mucosa oral puede ser el primer escenario de infección con SARS-CoV-2, debido a la especial afinidad que tiene el virus por las células con receptores para la ECA $2^{(5)}$ y que se encuentra altamente expresada en las células epiteliales de la lengua, el tracto respiratorio y las glándulas salivales (14); por lo que habría posibilidades de detectar lesiones orales que conlleven a determinar tempranamente la infección por COVID-19.
El tejido de la cavidad oral, al ser directamente infectado por el SARS-CoV-2 debido a la alta expresión del receptor ECA2 y a la afinidad con los receptores del ácido siálico podría proporcionar posibles rutas de entrada para el contagio del COVID-19 ${ }^{(15)}$, llegando a tener como consecuencia la pérdida del gusto y el olfato que se han reportado en la mayoría de los pacientes como síntomas del COVID - 19. Teniendo en cuenta que en un $91 \%$ de los pacientes que presentaron estos síntomas tuvieron alteraciones al gusto como síntoma inicial de la infección por SARS-CoV-2, incluso antes de la aparición de los síntomas respiratorios, por lo que se debe tener conocimiento de este síntoma, ya que se puede encontrar pacientes con alteraciones del gusto en forma de disgeusia, ageusia o hipogeusia ${ }^{(11,16)}$; siendo considerada como una de las principales manifestaciones relacionadas con la boca en pacientes con COVID-19 ${ }^{(5)}$. También se ha reportado sequedad de la boca y síndrome de boca ardiente (11,16), así como gingivitis descamativa (lesión de la encía marginal con descamación y eritema asociada a enfermedades mucocutáneas), úlceras y ampollas en la mucosa palatina compatibles con estomatitis herpética $y$ eritema localizado en el paladar y márgenes de la encía que se presenta con sensación de quemazón y dolor en la orofaringe ${ }^{(17)}$.

Vaira et al. (2020) evaluaron a 345 pacientes con COVID-19, de los cuales se detectó disgeusia en 36 casos $(10,4 \%), 119$ casos con hipogeusia leve, moderada o severa $(34,5 \%)$, mientras que en 190 casos $(55,1 \%)$ la función del gusto era normal ${ }^{(18)}$. Por otro lado, Lechien et al. (2020) reportaron que 342 pacientes $(88,8 \%)$ presentaron trastornos gustativos que se caracterizaron por el deterioro de las modalidades de sabor: salado, dulce, amargo y agrio $^{(19)}$.

Carreras et al. (2020) reportaron tres casos de manifestaciones orales asociadas a la infección por SARS-CoV-2, siendo estas, úlceras o ampollas, comúnmente observadas en otros procesos virales como fiebre aftosa, gingivoestomatitis herpética e infección oral por citomegalovirus. En los dos primeros casos se ubicaron en el tejido queratinizado, como suele observarse en lesiones orales de herpes simple y en el tercer caso, se encontró ubicada en el tejido queratinizado y no queratinizado, siendo más compatible con un eritema multiforme ${ }^{(20)}$. 
De acuerdo a las lesiones orofaciales asociadas a la COVID-19 que presentan los pacientes infectados, se observa que la distribución en hombres fue de $45,5 \%$ y en mujeres de $54,5 \%$. En cuanto a la ubicación de las lesiones orales, las lesiones en la mucosa especializada se presentaron en lengua en un $15,6 \%$ de los casos, las lesiones en la mucosa de revestimiento representan el $28,1 \%$ de los casos (en mucosa labial y carrillos) y la mucosa masticatoria se encuentra afectada en el 31,3\% de los casos (en mucosa gingival y paladar). El $25 \%$ de los reportes evaluados presentaron manifestaciones a nivel facial, entre ellos, casos de inflamación a causa de parotiditis, herpes orofacial y úlceras faciales por sesiones de intubación en posición de pronación (13)

Otras de las manifestaciones orales, a causa de los efectos secundarios por los medicamentos utilizados durante el tratamiento de la COVID-19 son: gingivitis ulcero necrotizante, enantema viral, y exantemas ${ }^{(21)}$, úlceras faciales por presión, papilas linguales prominentes, ampollas en la mucosa labial, boca seca, labios agrietados, y gingivitis descamativa ${ }^{(22)}$. Cabe recalcar que, estas manifestaciones podrían deberse a factores externos a la COVID-19 como el estrés, las reacciones a medicamentos y las enfermedades sistémicas de base.

\section{Lesiones orales producidas por coinfecciones o condiciones previas del paciente con COVID- 19}

Algunas manifestaciones orales en pacientes con COVID-19 se pueden producir como consecuencia de condiciones previas del paciente que lo hacen mas susceptible a complicaciones del cuadro viral del SARS-CoV-2. Entre las comorbilidades más prevalentes, reportadas en los casos de pacientes con COVID-19, tenemos: hipertensión (30,7\%), diabetes mellitus (14,3\%), considerada predictora de síntomas graves para la COVID-19 (23), enfermedad cardiovascular (11,9\%), enfermedad cerebrovascular $(6,6 \%)$, neoplasia maligna $(4,3 \%)$, enfermedad hepática crónica $(2,8 \%)$, enfermedad pulmonar crónica $(2,4 \%)$, enfermedad renal crónica $(2,1 \%)$, y VIH $(1,4 \%)$. Dentro de las complicaciones, se encuentra el síndrome de distrés respiratorio agudo y en los casos severos de COVID-19 se ha descrito injuria miocárdica, falla cardíaca, falla renal aguda, coinfección con virus respiratorio sincicial ${ }^{(24)}$.

En Italia, Milán, se llevó a cabo una investigación, donde se encontró que de 59 pacientes con SARSCoV-2, el $34 \%$ presentaba ageusia ${ }^{(25)}$, del mismo modo, en Corea del Sur reportaron que el 15,3\% (367) de los 3191 pacientes manifestaba ageusia, presentándose con mayor frecuencia en mujeres y personas jóvenes ${ }^{(26)}$.

Entre los pacientes evaluados, una mujer de 65 años con hipertensión arterial controlada y obesidad presentó lesiones ampollares en el labio, mientras que un paciente masculino de 58 años de edad quien padecía de diabetes e hipertensión arterial presentó gingivitis descamativa, úlceras y ampollas compatibles con estomatitis herpética recurrente en la mucosa palatina (20). Se observaron lesiones aftosas con necrosis y costras hemorrágicas, con mayor frecuencia, en pacientes ancianos con inmunosupresión e infección grave. De este grupo, un hombre de 67 años con enfermedad coronaria, ya revascularizada, hipertensión arterial sistémica, poliquistosis renal autosómica dominante y trasplante renal presentó áreas atróficas rodeadas de un halo amarilloblanco elevado clasificado como lengua geográfica (27)

Por otro lado, puede existir una coinfección bacteriana intraoral de géneros patógenos como: Prevotella intermedia, Fusobacterium nucleatum, Treponema pallidum y Porphyromona gingivalis en pacientes con enfermedad periodontal necrotizante que se manifiesta con un persistente estado inflamatorio y diferentes lesiones periodontales agudas ${ }^{(28)}$. Como es el caso de una mujer de 35 años, reportado por Patel y Woolley, que presentó gingivitis ulcerativa necrotizante asociadas a las bacterias antes mencionadas ${ }^{(29)}$, que han sido encontradas en grandes cantidades en pacientes con SARS-CoV-2 ${ }^{(30)}$ y que son conocidas como las principales causantes de lesiones periodontales agudas $^{(28)}$.

Por lo tanto, las enfermedades previas del paciente con COVID-19 (diabetes mellitus, inmunosupresión), las infecciones oportunistas, el estrés, el compromiso vascular, los traumatismos (secundarios a la intubación) y la respuesta hiperinflamatoria secundaria al COVID-19 podrían ser los factores predisponentes más importantes para el desarrollo de lesiones orales en pacientes con COVID-19 ${ }^{(31)}$ 
Tabla 1. Resumen de estudios relacionados sobre las manifestaciones orales en pacientes con COVID-

19

\begin{tabular}{|c|c|c|c|c|c|}
\hline AUTOR & $\begin{array}{l}\text { TIPO DE } \\
\text { ARTÍCULO }\end{array}$ & $\begin{array}{l}\text { ANTECEDENTES } \\
\text { MÉDICOS }\end{array}$ & COVID-19 & $\begin{array}{l}\text { MANIFESTACIONES } \\
\text { GENERALES }\end{array}$ & $\begin{array}{l}\text { MANIFESTACIONES } \\
\text { ORALES }\end{array}$ \\
\hline $\begin{array}{l}\text { Biadsee et } \\
\text { al. (4) }\end{array}$ & $\begin{array}{l}\text { Artículo } \\
\text { Original }\end{array}$ & No presenta & Positivo & $\begin{array}{l}\text { Tos, fiebre, mialgia, } \\
\text { debilidad muscular, } \\
\text { dolor de garganta, } \\
\text { congestión nasal y } \\
\text { rinorrea }\end{array}$ & $\begin{array}{l}\text { Xerostomía, disgeusia, } \\
\text { sensibilidad en la } \\
\text { lengua, hinchazón en la } \\
\text { cavidad oral }\end{array}$ \\
\hline Mija et al. (5) & $\begin{array}{l}\text { Artículo de } \\
\text { Revisión }\end{array}$ & No presenta & Positivo & $\begin{array}{c}\text { Fiebre, tos seca, } \\
\text { congestión nasal, fatiga, } \\
\text { alto } \\
\text { erupción eritematosa, } \\
\text { urticaria localizada o } \\
\text { generalizada, pérdida } \\
\text { del gusto y del olfato }\end{array}$ & $\begin{array}{l}\text { Gingivitis descamativa, } \\
\text { úlceras y ampollas c } \\
\text { ompatibles con est } \\
\text { omatitis herpética rec } \\
\text { urrente en la mucosa } \\
\text { palatina, } \\
\text { Sensación de } \\
\text { quemazón y dolor de la } \\
\text { orofaringe }\end{array}$ \\
\hline $\begin{array}{c}\text { Sinjari et al. } \\
(6)\end{array}$ & $\begin{array}{l}\text { Artículo } \\
\text { Original }\end{array}$ & No presenta & Positivo & $\begin{array}{l}\text { Fiebre, cansancio, tos } \\
\text { seca, dolores } \\
\text { musculares, congestión } \\
\text { nasal, secreción nasal, } \\
\text { dolor de garganta o } \\
\text { diarrea, neumonía, } \\
\text { síndrome respiratorio } \\
\text { agudo severo, } \\
\text { insuficiencia renal }\end{array}$ & $\begin{array}{c}\text { Hipogeusia, xerostomía } \\
\text { y alteraciones } \\
\text { quimiosensoriales }\end{array}$ \\
\hline
\end{tabular}




\begin{tabular}{|c|c|c|c|c|c|}
\hline $\begin{array}{c}\text { Gutiérrez et } \\
\text { al. (8) }\end{array}$ & $\begin{array}{l}\text { Artículo de } \\
\text { Revisión }\end{array}$ & $\begin{array}{l}\text { Hipertensión } \\
\text { arterial } \\
\text { controlada y } \\
\text { obesidad }\end{array}$ & Positivo & $\begin{array}{l}\text { Fiebre, síntomas } \\
\text { respiratorios y } \\
\text { gastrointestinales }\end{array}$ & $\begin{array}{c}\text { Sequedad de boca, } \\
\text { hipogeusia, disgeusia, } \\
\text { ageusia, } \\
\text { lesiones ulcerativas de } \\
\text { color naranja y } \\
\text { amarillentas } \\
\text { puntiformes con halo } \\
\text { eritematoso, distribución } \\
\text { simétrica en el paladar } \\
\text { duro, } \\
\text { gingivitis descamativa y } \\
\text { estomatitis herpética }\end{array}$ \\
\hline
\end{tabular}

\begin{tabular}{|c|c|c|c|c|c|}
\hline $\begin{array}{l}\text { Parra et al. } \\
\text { (13) }\end{array}$ & $\begin{array}{l}\text { Artículo } \\
\text { Original }\end{array}$ & No presenta & Positivo & $\begin{array}{l}\text { Fiebre, tos seca, fatiga, } \\
\text { expectoración, cefalea }\end{array}$ & $\begin{array}{l}\text { Ulceración en el dorso } \\
\text { lingual, disgeusia, } \\
\text { estomatitis, xerostomía, } \\
\text { parotiditis, alteraciones } \\
\text { en la mucosa oral, } \\
\text { lesiones eritematosas, } \\
\text { ampollas, petequias, } \\
\text { gingivitis ulcero } \\
\text { necrotizante y gingivitis } \\
\text { descamativa }\end{array}$ \\
\hline
\end{tabular}

\begin{tabular}{|c|c|c|c|c|c|}
\hline $\begin{array}{l}\text { Nemet et al. } \\
\text { (14) }\end{array}$ & $\begin{array}{l}\text { Artículo de } \\
\text { Revisión }\end{array}$ & No presenta & Positivo & $\begin{array}{c}\text { Fiebre, tos seca, diarrea } \\
\text { y dificultad respiratoria }\end{array}$ & $\begin{array}{c}\text { Hiposalivación, } \\
\text { xerostomía, ageusia, } \\
\text { hipogeusia, disgeusia, } \\
\text { lesiones herpéticas y } \\
\text { candidiasis }\end{array}$ \\
\hline $\begin{array}{l}\text { Lechien et al. } \\
\text { (19) }\end{array}$ & $\begin{array}{l}\text { Artículo } \\
\text { Original }\end{array}$ & No presenta & Positivo & $\begin{array}{l}\text { Anorexia, artralgia, } \\
\text { mialgia, fatiga, cefalea, } \\
\text { dolor abdominal, } \\
\text { urticaria y disnea }\end{array}$ & $\begin{array}{c}\text { Disgeusia, dolor facial, } \\
\text { otalgia y parotiditis }\end{array}$ \\
\hline $\begin{array}{l}\text { Carreras et } \\
\text { al. (20) }\end{array}$ & $\begin{array}{l}\text { Artículo de } \\
\text { Reporte de } \\
\text { Caso }\end{array}$ & $\begin{array}{c}\text { Hipertensión } \\
\text { controlada, } \\
\text { obesidad, diabetes e } \\
\text { hipertensión }\end{array}$ & Positivo & $\begin{array}{c}\text { Fiebre, astenia, } \\
\text { disgeusia, diarrea, } \\
\text { neumonía, erupciones } \\
\text { cutáneas debajo de los } \\
\text { senos, espalda y área } \\
\text { genital }\end{array}$ & $\begin{array}{c}\text { Ampollas en mucosa } \\
\text { labial, dolor en lengua, } \\
\text { gingivitis descamativa, } \\
\text { posible estomatitis } \\
\text { herpética recurrente y } \\
\text { múltiples úlceras en } \\
\text { paladar }\end{array}$ \\
\hline
\end{tabular}




\begin{tabular}{|c|c|c|c|c|c|}
\hline $\begin{array}{l}\text { Patel et al. } \\
\quad(21)\end{array}$ & $\begin{array}{l}\text { Carta al } \\
\text { Editor }\end{array}$ & No presenta & Positivo & $\begin{array}{l}\text { Fiebre, linfadenopatía } \\
\text { submandibular bilateral }\end{array}$ & $\begin{array}{l}\text { Gingivitis ulcerativa } \\
\text { necrotizante }\end{array}$ \\
\hline $\begin{array}{l}\text { Hjelmesaeth } \\
\text { et al. } \\
\text { (25) }\end{array}$ & $\begin{array}{l}\text { Artículo de } \\
\text { Reporte de } \\
\text { Raso }\end{array}$ & No presenta & Positivo & Síntomas respiratorios & Disgeusia \\
\hline $\begin{array}{l}\text { Lee et al. } \\
\quad(26)\end{array}$ & $\begin{array}{l}\text { Artículo de } \\
\text { Revisión }\end{array}$ & No presenta & Positivo & $\begin{array}{l}\text { Fiebre alta ,tos seca; } \\
\text { disnea, mialgia, } \\
\text { confusión, dolor de } \\
\text { cabeza, dolor de } \\
\text { garganta, rinorrea, dolor } \\
\text { de pecho, diarrea, } \\
\text { náuseas/vómitos, } \\
\text { congestión conjuntival, } \\
\text { producción de esputo, } \\
\text { fatiga, hemoptisis y } \\
\text { escalofríos }\end{array}$ & Anosmia, ageusia \\
\hline
\end{tabular}

Fuente: Elaboración propia

\section{Recomendaciones para el control de la higiene oral en pacientes con COVID-19}

Los cuidados bucodentales, como medida profiláctica, adquieren una gran importancia durante este momento de incertidumbre y riesgo para la salud general, ya que una higiene bucal deficiente es un factor de riesgo que puede afectar de algún modo al organismo. Entre las medidas que debemos tomar para el autocuidado de la cavidad oral como para la prevención de la transmisión del COVID-19, se incluyen el uso de colutorios de cloruro de cetilpiridinio (CPC), el cual se recomienda a diario y se puede emplear a largo plazo; tiene una sustantividad de 3 a 5 horas y puede ayudar a controlar la carga microbiana oral; siendo útil enjuagarse tres veces al día durante el proceso activo del COVID-19 ya que se ha visto que inactiva la envoltura de la capa lipídica del virus ${ }^{(32)}$. Otra recomendación, en cuanto al uso de cepillos de dientes, es que estos deben enjuagarse con abundante agua, ser almacenados en posición vertical y dejar secar al aire libre y cambiarlo tras un proceso infeccioso por COVID-19, aunque aún no se sabe la capacidad de reinfección de este virus, el cepillo podría ser el transmisor del virus al resto de la familia ${ }^{(33)}$. Por ello, el odontólogo tiene la responsabilidad de orientar a sus pacientes sobre el cuidado de salud bucal y enfermedades relacionadas a esta, así mismo es importante su participación activa en la identificación de las manifestaciones clínicas relacionadas al COVID19, derivando a estos pacientes a una atención especializada para interrumpir la cadena de transmisión.

\section{CONCLUSIÓN}

Se ha evidenciado que la cavidad oral es la puerta de entrada para la infección por SARS-CoV-2 debido a la especial afinidad del virus con los receptores ECA2 y el ácido siálico presentes en las células de la mucosa oral, lengua y glándulas salivales, razón por la cual, las principales manifestaciones orales reportadas en la literatura son la disgeusia, ageusia, hipogeusia, sequedad de la boca, gingivitis descamativa, úlceras o ampollas en la mucosa palatina y eritema localizado en el paladar y márgenes de la encía. Por otro lado, hay evidencia que algunas manifestaciones orales como gingivitis descamativa, úlceras, ampollas compatibles con estomatitis herpética recurrente, áreas atróficas rodeadas de un halo amarilloblanco elevado clasificado como lengua geográfica en pacientes con COVID-19 se pueden producir por coinfecciones de patógenos oportunistas como consecuencia del estado susceptible del paciente. De tal manera que, es de vital importancia que los profesionales de salud de la Odontología reconozcan estas implicaciones para un posible diagnóstico temprano y establecer un tratamiento oportuno.

Fuente de financiamiento: El estudio fue 
financiado por los autores.

Contribuciones de autoría: Todos los autores contribuyeron de la misma manera en la búsqueda, análisis de la literatura y elaboración del artículo. Todos los autores aprueban el artículo y su envío para publicación.

Conflicto de intereses: Los autores declaran no poseer conflicto de intereses en la presente investigación.

\section{REFERENCIAS BIBLIOGRÁFICAS}

1. Maguiña C, Gastelo R, Tequen A. El nuevo Coronavirus y la pandemia del Covid-19. Rev Med Hered [Internet]. 2020 Abr [citado 2021 Ene 13]; 31(2):125-131. Disponible en:

http://www.scielo.org.pe/scielo.php?script=sci_arttext\&pid= S1018-130X2020000200125\&Ing=es

2. Muniz I, Linden L, Santos M, Rodrigues R, Souza J, Oliveira R, et al. SARS-CoV-2 and Saliva as a Diagnostic Tool: A Real Possibility. Pesqui Bras Odontopediatria Clín Integr [Internet]. 2020 [citado 2021 Ene 13]; 20(suppl 1): e0112.

Disponible

en:

http://www.scielo.br/scielo.php?script=sci_abstract\&pid=S1 983-46322020001500803\&lng=en\&nrm=iso\&tlng=en

3. Ren Y, Rasubala L, Malmstrom H, Eliav E. Dental Care and Oral Health under the Clouds of COVID-19. JDR Clin Trans Res [Internet]. 2020 [citado 2021 Ene 13]; 5(3):202210. Disponible

en:

https://journals.sagepub.com/doi/pdf/10.1177/23800844209 24385

4. Biadsee A, Biadsee A, Kassem F, Dagan O, Masarwa S, Ormianer Z. Olfactory and Oral Manifestations of COVID19: Sex-Related Symptoms-A Potential Pathway to Early Diagnosis. Otolaryngol. Head Neck Surg. 2020 [citado 2021 Ene 13]; 163(4):722-728. Disponible en: https://journals.sagepub.com/doi/full/10.1177/01945998209 34380

5. Mija Gómez J. COVID-19 y su trascendencia en la atención dental: revisión y actualización de la literatura. Odontol Sanmarquina [Internet]. 2020 Jul 8 [citado 2021 Ene 13]; 23(3):261-70. Disponible en: https://revistasinvestigacion.unmsm.edu.pe/index.php/odon t/article/view/18130

6. Sinjari B, D'Ardes D, Santilli M, Rexhepi I, D'Addazio G, Di Carlo P, et al. SARS-CoV-2 and Oral Manifestation: An Observational, Human Study. J Clin Med. 2020 Oct 7 [citado 2021 Ene 13]; 9(10):3218. Disponible en: https://www.ncbi.nlm.nih.gov/pmc/articles/PMC7600761/

7. Rocafuerte M. La saliva y su papel en la trasmisión del covid-19 - lo que el odontólogo necesita saber. Revista KIRU [Internet]. 2020 May 25 [citado 2021 Ene 15]; 17(2). Disponible

https://www.aulavirtualusmp.pe/ojs/index.php/Rev-

Kiru0/article/view/1888

8. Gutiérrez Flores R, Zambrano Rodríguez G. Implicaciones bucales por COVID-19. Revisión de tema. Odontol Sanmarquina [Internet]. 2020 Nov 13 [citado 2021 Ene 15]; 23(4):419-23. Disponible en: https://revistasinvestigacion.unmsm.edu.pe/index.php/odon t/article/view/19104
9. Portocarrero J, Alvarez $\mathrm{H}$. Odontología en el contexto COVID-19: Una vista actual. J Oral Res. 2020 [citado 2021 Ene 15]; Covid-19. S2(1):23-30. Disponible en: https://revistasacademicas.udec.cl/index.php/journal_of_or al research/article/download/2514/2776/4578

10. Ramírez M, Medina P, Morocho A. Enfermedad por coronavirus 2019 (COVID-19) y su repercusión en la consulta odontológica: una revisión. Odontol Sanmarquina [Internet]. 2020 May 6 [citado 2021 Ene 15]; 23(2):139-46. Disponible en: https://revistasinvestigacion.unmsm.edu.pe/index.php/odon t/article/view/17758

11. Odeh N, Babkair H, Abu-Hammad S, Borzangy S, AbuHammad A, Abu-Hammad O. COVID-19: Present and Future Challenges for Dental Practice. Int J Environ Res Public Health. 2020 Apr 30 [citado 2021 Ene 15]; 17(9):3151. Disponible en: https://www.ncbi.nlm.nih.gov/pmc/articles/PMC7246705/

12. Aguilar V, Benavides E. Actitud ante el COVID-19 en la práctica dental rutinaria. Rev Ciencias Médicas [Internet]. 2020 [citado 2021 Ene 15]; 24(3): e4463. Disponible en: http://revcmpinar.sld.cu/index.php/publicaciones/article/vie w/4463

13. Parra E, Bermúdez $M$, Peña $C$, Rueda $A$. Manifestaciones orales y maxilofaciales asociadas a la COVID-19. Revisión de la literatura. Acta Odont Col. 2020 [citado 2021 Ene 16]; 10(Supl. COVID-19):60-80. Disponible

https://revistas.unal.edu.co/index.php/actaodontocol/article/ view/89447

14. Nemeth M, Matus C, Carrasco R. Manifestaciones orales de la infección por COVID-19. Int. J. Odontostomat. 2020 [citado 2021 Ene 16]; 14(4):555-560. Disponible en: http://www.ijodontostomatology.com/es/articulo/manifestaci ones-orales-de-la-infeccion-por-covid-19/

15. Xu H, Zhong L, Deng J, et al. High expression of ACE2 receptor of 2019-nCoV on the epithelial cells of oral mucosa. Int J Oral Sci. [Internet]. 2020 [citado 2021 Ene 16]; 12,8. Disponible en: https://www.nature.com/articles/s41368-020-0074-x

16. Chen L, Zhao J, Peng J, Li X, Deng X, Geng Z, et al. Detection of 2019-nCoV in Saliva and Characterization of Oral Symptoms in COVID-19 Patients. 2020 Mar 14 [citado 2021 Ene 16]. Disponible en: https://ssrn.com/abstract $=3557140$

17. Vieira A. Oral Manifestations in Coronavirus Disease 2019 (COVID-19). Oral Dis. [Internet]. 2020 Jun [citado 2021 Ene 16]. Disponible en: https://onlinelibrary.wiley.com/doi/full/10.1111/odi.13463 18. Vaira L, Salzano G, Deiana G, De Riu G. Anosmia and Ageusia: Common Findings in COVID-19 Patients. Laryngoscope. [Internet]. 2020 Jul [citado 2021 Ene 17];130(7):1787. Disponible en: https://pubmed.ncbi.nlm.nih.gov/32237238Quispe Vargas. et al

19. Lechien J, Chiesa C, De Siati D, Horoi M, Le Bon S, Rodríguez $\mathrm{A}$, et al. Olfactory and gustatory dysfunctions as a clinical presentation of mild-to-moderate forms of the coronavirus disease (COVID-19): a multicenter European study. Eur Arch Oto-Rhino-Laryngology. 2020 [citado 2021 Ene 17]; 277(8): 2251-2261. Disponible en: https://pubmed.ncbi.nlm.nih.gov/32253535/

20. Carreras-Presas, C. M.; Amaro Sánchez, J.; LópezSánchez, A. F.; Jané-Salas, E. \& Somacarrera Pérez, M. L. Oral vesiculobullous lesions associated with SARS-CoV-2 infection. Oral Dis., 2020 [citado 2021 Ene 17]. Disponible en: https://onlinelibrary.wiley.com/doi/full/10.1111/odi.13382 21. Patel J, Woolley J. Letter to the editor. Necrotizing periodontal disease: Oral 
manifestation of COVID-19. Oral Dis. 2020 [citado 2021 Ene 17]; 00: 1-2. Disponible en: https://onlinelibrary.wiley.com/doi/10.1111/odi.13462

22. Carreras M, Amaro J, López A, Jané E, Somacarrera M. Oral vesiculobullous lesions associated with SARS-CoV-2 infection. Oral Dis. 2020 [citado 2021 Ene 18]; 00: 1-3. Disponible https://onlinelibrary.wiley.com/doi/full/10.1111/odi.13382

23. Sepúlveda C, Waissbluth A, González G. Anosmia y enfermedad por Coronavirus 2019 (COVID-19): ¿Qué debemos saber? Rev. Otorrinolaringol. Cir. Cabeza Cuello [Internet]. 2020 Jun [citado 2021 Ene 18]; 80(2): 247258. Disponible

en:

https://scielo.conicyt.cl/scielo.php?script=sci_arttext\&pid=S0 718-48162020000200247\&lng=es.

24. Yang X, Yu Y, Xu J, Shu H, Xia J, Liu H, et al. Clinical course and outcomes of critically ill patients with SARSCoV-2 pneumonia in Wuhan, China: a single-cente-red, retrospective, observational study. Lancet Respir Med. 2020 [citado 2021 Ene 18]; 8(5): 475-481. Disponible en: https://pubmed.ncbi.nlm.nih.gov/32105632/

25. Hjelmesaeth J, Skaare D. Loss of smell or taste as the only symptom of COVID-19. Tidsskr Nor Laegeforen. J Korean Med Sci. 2020 [citado 2021 Ene 19];140(7). Disponible https://www.ncbi.nlm.nih.gov/pubmed/32378854

26. Lee Y, Min P, Lee S, Kim S. Prevalence and Duration of Acute Loss of Smell or Taste in COVID19 Patients. J Korean Med Sci. 2020 [citado 2021 Ene 19];35(18): e174. Disponible https://pesquisa.bvsalud.org/portal/resource/\%20es/mdl32383370

27. Amorim J, Normando A, Carvalho R, De Paula R, Cembranel A, Santos A y Guerra E. Oral mucosal lesions in a COVID-19 patient: ¿New signs or secondary manifestations? IJID. 2020 [citado 2021 Ene 19], 97, 326328.

https://www.sciencedirect.com/science/article/pii/S1201971 220304471
28. Herrera D, Retamal B, Alonso B, Feres M. Acute periodontal lesions (periodontal abscesses and necrotizing periodontal diseases) and endo-periodontal lesions. J Periodontol. 2018 [citado 2021 Ene 21]; 45(S20): 78-94. Disponible en: https://pubmed.ncbi.nlm.nih.gov/29926942/

29. Patel J, Woolley J. Letter to the editor. Necrotizing periodontal disease: Oral manifestation of COVID 19. Oral Dis. 2020 [citado 2021 Ene 20]; 00: 1-2. Disponible https://onlinelibrary.wiley.com/doi/10.1111/odi.13462

$30 . \quad$ Chakraborty S. Letter to the Editor. Metagenome of SARS-Cov2 patients in Shenzhen with travel to Wuhan shows a wide range of species - Lautropia, Cutibacterium, Haemophilus being most abundant - and Campylobacter explaining diarrhea. OSF Prepr. 2020 Mar 24 [citado 2021 Ene 20]; (Preprint): 1-3. Disponible en: https://osf.io/jegwq

31. Iranmanesh B, Khalili M, Amiri R, Zartab H, Aflatoonian M. Oral manifestations of COVID-19 disease: A review article. Dermatologic Therapy. 2020 Nov 25 [citado 2021 Ene 21]: e14578. Disponible en: https://onlinelibrary.wiley.com/doi/full/10.1111/dth.14578

32. Sigua E, Bernal J, Lanata A, Sánchez C, Rodríguez J, Haidar S, et al. COVID-19 y la Odontología: Una Revisión de las Recomendaciones y Perspectivas para Latinoamérica. Int. J. Odontostomat. [Internet]. 2020 Sep [citado 2021 Ene 21]; 14(3): 299-309. Disponible en: https://scielo.conicyt.cl/scielo.php?script=sci_arttext\&pid=S0 718-381X2020000300299\&Ing=es.

33. Díaz F, Huerta J. Protocolo de Higiene Oral para Establecimientos de Larga Estadía para Adultos Mayores en Estado de Pandemia COVID-19. Prevención de Neumonía por Aspiración. Int. J. Odontostomat. [Internet]. 2020 Dic [citado 2021 Ene 21];14(4): 508-512. Disponible en:

https://scielo.conicyt.cl/scielo.php?script=sci_arttext\&pid=S0 718-381X2020000400508\&Ing=es.

\author{
Yessica del Rocio Quispe-Vargas \\ ORCID https://orcid.org/0000-0001-9582-144X \\ yessica.quispe@unmsm.edu.pe \\ Lesly Coraly La Serna-Ojeda \\ ORCID \\ lesly.laserna@unmsm.edu.pe \\ María Lizeth Floreano-Calero \\ ORCID (D) https://orcid.org/0000-0001-8763-8688 \\ maria.floreano1@unmsm.edu.pe \\ Manuel Antonio Mattos-Vela. \\ ORCID (D) https://orcid.org/0000-0002-5701-1961 \\ mmattosv@unmsm.edu.pe
}

Copyright ( ) La revista. La revista Kiru es publicada por la Facultad de Odontología de la Universidad de San Martín de Porres, en Lima, Perú. 